\title{
Affinities of Treponema pallidum for human lactoferrin and transferrin
}

\author{
J F ALDERETE, K M PETERSON, J B BASEMAN \\ From the Department of Microbiology, The University of Texas Health Science Center at San Antonio, Texas, \\ USA
}

SUMMARY The acquisition of lactoferrin and transferrin by live Treponema pallidum organisms was examined. Saturation binding kinetics were obtained for virulent treponemes with increasing amounts of radioiodinated lactoferrin but not with transferrin. Furthermore, lactoferrin bound up to 100 times more effectively than transferrin. Only unlabelled lactoferrin stoichiometrically competed with iodinated lactoferrin binding. Time course kinetics showed maximum lactoferrin acquisition within the first five minutes at $34^{\circ} \mathrm{C}$. Optimum iron accumulation, however, was achieved by $T$ pallidum in 30 minutes at $34^{\circ} \mathrm{C}$, and amounts of iron were six times greater than the equivalent amount of lactoferrin bound. Interestingly, iron uptake was also detected in the presence of transferrin, despite the minimal amounts of transferrin acquired by live treponemes. These observations reinforce the possibility that the associations of $T$ pallidum with host molecules, such as plasma proteins, are essential for survival of the parasite within host environments.

The ability of Treponema pallidum to selectively coat itself with specific host components appears to represent an important and critical property, which contributes to the virulence of the syphilis spirochaetes. For example, the masking of important treponemal immunogens, which would otherwise be targets of host immune surveillance leading to immobilisation or neutralisation of the treponemes, appears to be an important property of virulent treponemes. ${ }^{1-3}$ In other studies designed to examine the relevance of the association of specific host plasma proteins with treponemal surfaces, ${ }^{4}$ we estimated that up to 12 plasma proteins specifically and avidly bound to $T$ pallidum only, and not to the avirulent spirochaete, $T$ phagedenis biotype Reiter. These approaches led to the discovery of fibronectin as the receptor for treponemal adherence to host cells and extracellular matrix. ${ }^{47}$ Three outer envelope proteins of $T$ pallidum were found to bind to fibronectin in a receptor to ligand fashion. ${ }^{458}$

Studies have shown that serum components enhance the survival of $T$ pallidum in a microaerophilic

Address for reprints: $\operatorname{Dr}$ John $\mathrm{F}$ Alderete, Department of Microbiology, University of Texas Health Science Center at San Antonio, 7703 Floyd Curl Drive, San Antonio, Texas 78284-7758, USA

Accepted for publication 1 July 1988 acellular environment. ${ }^{9-13}$ Transferrin was found to promote treponemal motility to levels equal to those observed in the presence of serum. ${ }^{13}$ An earlier study had also found that this iron binding protein bound to $T$ pallidum. ${ }^{2}$ Because of the inability to cultivate these virulent spirochaetes in vitro and the putative role of serum proteins such as transferrin in treponemal survival, we examined the binding of transferrin as well as of lactoferrin, another protein that binds iron, to $T$ pallidum surfaces. In this report we present evidence that iron accumulates as a result of either transferrin or lactoferrin associating with treponemes, which indicates that the Nichols strain of $T$ pallidum sequesters iron from host macromolecules during systemic and mucosal infections.

\section{Materials and methods}

\section{BACTERIA}

$T$ pallidum organisms were harvested from the infected testes of New Zealand white rabbits. Testicular tissue from peak orchitis was minced, and treponemes were extracted by shaking the minced tissue in 15 to $20 \mathrm{ml}$ of a salts and glucose medium under reducing conditions. ${ }^{245}$ Organisms were clarified of host cellular debris as described previously, and the bacteria were pelleted and resuspended at a density range of $0 \cdot 1$ to $3.0 \times 10^{10} \mathrm{ml}$. 


\section{LACTOFERRIN AND TRANSFERRIN PROTEIN PREPARATIONS}

Human milk lactoferrin was either purified by heparin and agarose chromatography as detailed previously ${ }^{14}$ or purchased from Sigma Chemical, St Louis, Missouri, USA. Lactoferrin and transferrin (Sigma) were more than $99 \%$ pure, as assessed by $7.5 \%$ polyacrylamide gel electrophoresis and staining. ${ }^{14}$ Protein solutions of lactoferrin and transferrin were prepared in phosphate buffered saline (PBS), ${ }^{14} \mathrm{pH} 7 \cdot 4$. The proteins were charged with iron by dialysing lactoferrin and transferrin overnight against two changes of $100 \mathrm{mmol} / 1$ citrate acetate buffer $(\mathrm{pH} \mathrm{4.0)}$ followed by one change each of distilled water and $40 \mathrm{mmol} / 1$ trometamol (tris(hydroxymethyl) aminomethane) (Trizma base; Sigma) with $20 \mathrm{mmol} / 1$ sodium bicarbonate buffer ( $\mathrm{pH} 7 \cdot 4) .{ }^{14}$ Transferrin and lactoferrin were saturated with iron by adding $30 \mu \mathrm{g}$ ferric chloride to $5 \mathrm{mg}$ protein in the trometamol (tris) and bicarbonate buffer. Unbound iron was removed by dialysis against PBS. Analytical grade water from a Milli-Q water purification system was used for all buffers and protein solutions.

Lactoferrin and transferrin were radioiodinated by lactoperoxidase as described previously ${ }^{14}$ using $1.0 \mathrm{mCi}$ sodium radioiodine $\left(\mathrm{Na}^{125} \mathrm{I}\right.$; Amersham, Arlington Heights, Illinois, USA). Free radioisotope was removed using a $1 \times 20 \mathrm{~cm}$ Sephadex G-25 column (Pharmacia, Piscataway, New Jersey, USA). Efficiency of labelling was measured by the precipitation of proteins by trichloroacetic (now called trichloroethanoic) acid.

For studies examining the uptake and accumulation of ferric iron, radioiron chloride $\left({ }^{59} \mathrm{FeCl}_{3} ;\right.$ Amersham) was added to lactoferrin and transferrin as above in the TRIS and bicarbonate buffer for $\mathbf{3 0}$ minutes at $22^{\circ} \mathrm{C}$. Unincorporated iron was removed by chromatography in a $1 \times 10 \mathrm{~cm}$ Sephadex G25 column, followed by overnight dialysis against two changes of PBS. These radiolabelled preparations were about half saturated with radioiron $\left({ }^{59} \mathrm{Fe}\right)$ as measured by incorporated radioactivity.

\section{BINDING ASSAYS}

Aliquots of $0 \cdot 1$ to $3.0 \times 10^{10}$ treponemes were added to siliconised $1.5 \mathrm{ml}$ microcentrifuge tubes containing no more than $100 \mu \mathrm{l}$ lactoferrin or transferrin protein solutions. The final volume was adjusted to $0.5 \mathrm{ml}$. After the spirochaete and protein mixture had been incubated at $4^{\circ} \mathrm{C}$ or $34^{\circ} \mathrm{C}$ for designated times, the organisms were pelleted, washed twice in PBS, resuspended, placed in a new siliconised microcentrifuge tube, and finally washed in PBS. Radioactivity associated with the pellet was then measured to estimate the bound proteins. (a)
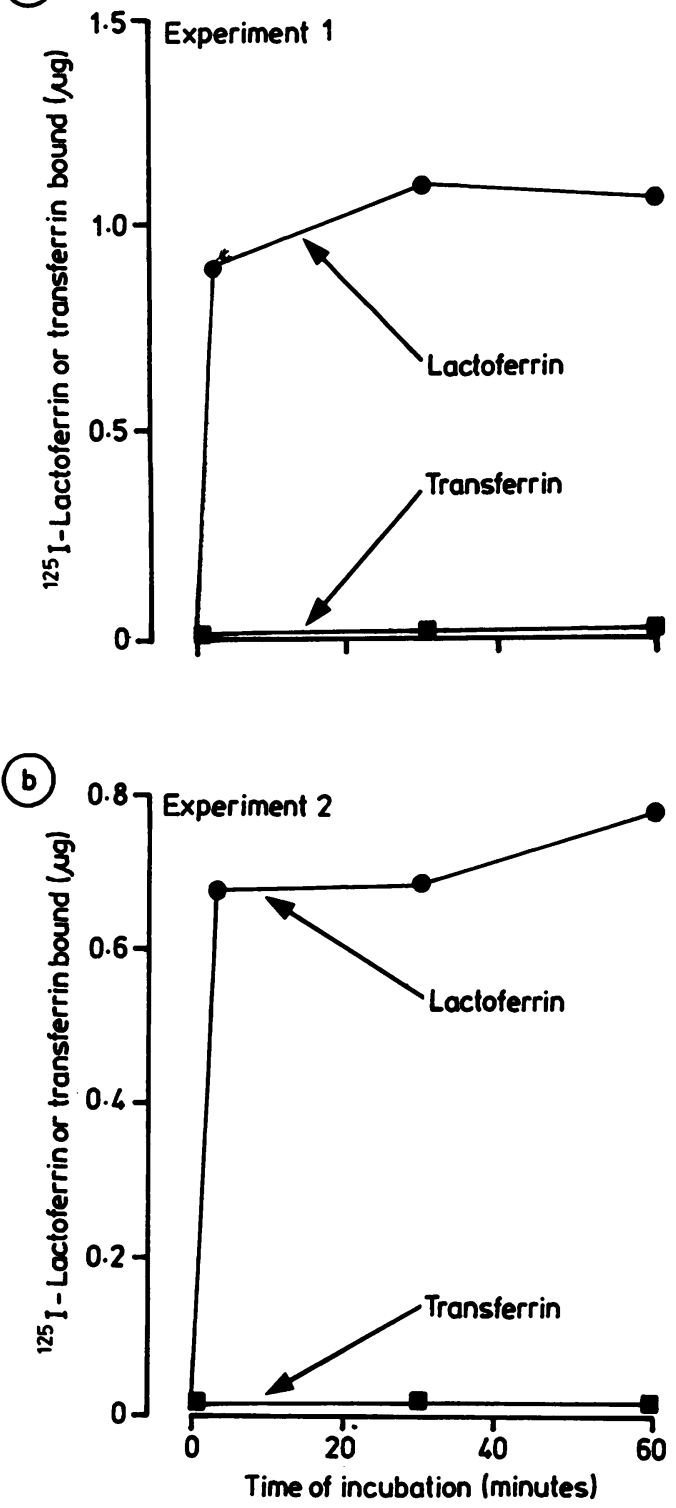

Fig 1 Results of duplicates of two experiments, each using treponemes extracted from testicular tissue from different rabbits, showing time taken for radioiodinated ( ${ }^{25}$ I-labelled) human lactoferrin and transferrin to bind to Treponema pallidum. (Treponemes suspended at density of $2.4 \times 10^{10}$ organisms in $0.5 \mathrm{ml}$ final volume and incubated with $133 \mu \mathrm{g}$ iodinated lactoferrin or transferrin. Specific activity of lactoferrin was $7.0 \times 10^{5}$ counts per minute $(\mathrm{cpm}) / \mu \mathrm{g}$ and of transferrin was $5.0 \times 10^{5} \mathrm{cpm} / \mu \mathrm{g}$. Amount of associated radioactivity assessed as described in text under Materials and methods.) 
Results

BINDING OF LACTOFERRIN AND TRANSFERRIN DEPENDENT ON TIME AND TEMPERATURE

Because of the potential role of iron binding host proteins in treponemal survival, ${ }^{13}$ we examined the kinetics of binding of ${ }^{125} \mathrm{I}$-labelled human transferrin and lactoferrin to freshly extracted $T$ pallidum. Figure 1 shows the time taken for iodinated transferrin and lactoferrin to bind to $T$ pallidum. Surprisingly, little or no accumulation of transferrin was noted in contrast to the increased saturable binding of lactoferrin under the same conditions. Overall, the amount of lactoferrin acquired after saturation was more than 100 times that of transferrin. Rates of acquisition and amount of lactoferrin bound were similar at both $34^{\circ} \mathrm{C}$ and $4^{\circ} \mathrm{C}$ (data not shown), and saturation was achieved very rapidly (in less than five minutes) followed by steady binding for the remainder of the assay.

After maximum binding of ${ }^{125}$ I-lactoferrin had been achieved (after 30 minutes), further incubation of treponemes in the absence of exogenous lactoferrin resulted in the release of ${ }^{125} \mathrm{I}$-lactoferrin (table). About half the bound lactoferrin dissociated from intact organisms after incubation for an additional 30 minutes. The counts per minute (cpm) were measured in the supernatant. Released radioactivity was analysed electrophoretically, and no alteration in the mobility of lactoferrin was observed, which showed that the treponemes had not degraded bound lactoferrin.

\section{BINDING OF ${ }^{125}$ I-LABELLED LACTOFERRIN} DEPENDENT ON CONCENTRATION

Figure 2 shows lactoferrin binding after treponemes had been incubated with increasingly large amounts of

Table Time dependent release of ${ }^{125}$ I-lactoferrin from surfaces of Treponema pallidum*

\begin{tabular}{llll}
\hline $\begin{array}{l}\text { Time of incubation } \\
\text { (minutes) }\end{array}$ & $\begin{array}{l}\text { Incubation } \\
\text { temperature }\end{array}$ & \multicolumn{2}{c}{$\begin{array}{l}\text { Counts per minute associated } \\
\text { with T pallidum (\% remaining) }\end{array}$} \\
\hline 0 & & 395494 & $(100)$ \\
15 & & 213192 & $(54)$ \\
30 & $4^{\circ} \mathrm{C}$ & 210640 & $(53)$ \\
60 & & 210528 & $(53)$ \\
0 & & 522810 & $(100)$ \\
15 & & 277738 & $(53)$ \\
30 & $34^{\circ} \mathrm{C}$ & 396734 & $(76)$ \\
60 & & 299894 & $(57)$ \\
\hline
\end{tabular}

$* 8.5 \times 10^{9}$ organisms in $0.5 \mathrm{ml}$ final volume incubated with $100 \mu \mathrm{g}$ ${ }^{125}$ I-labelled lactoferrin (specific activity $6.6 \times 10^{5} \mathrm{cpm} / \mu \mathrm{g}$ ) at $4^{\circ} \mathrm{C}$ and $34^{\circ} \mathrm{C}$ for 30 minutes. After being incubated at specified temperatures, treponemes were washed with PBS and transferred to new siliconised microcentrifuge tube. Radioactivity of organisms and supernatant was measured after pelleting organisms. Each result represents mean of duplicate samples from representative experiment.

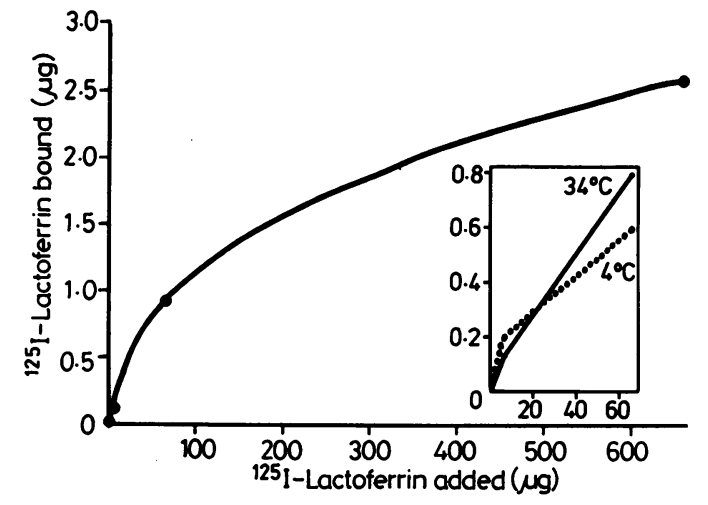

Fig 2 Binding of radioiodinated ( ${ }^{125}$ I-labelled) human lactoferrin to $T$ pallidum dependent on concentration of lactoferrin. (Bacteria were suspended at density of $3.2 \times 10^{9}$ in $0.5 \mathrm{ml} \mathrm{PBS}$ and incubated with increasing concentrations of ligand for 30 minutes at $34^{\circ} \mathrm{C}$. Inset shows same rates of ligand binding at $34^{\circ} \mathrm{C}$ and $4^{\circ} \mathrm{C}$. Using $66 \mu \mathrm{g}$ and $660 \mu \mathrm{g},{ }^{125} \mathrm{I}-$ labelled transferrin bound $0.017 \mu \mathrm{g}$ and $0.12 \mu \mathrm{g}$ transferrin, which represented $2 \%$ and $4 \%$ of lactoferrin acquired by treponemes under same conditions. Specific activities of both iodinated lactoferrin and of transferrin were $3.5 \times 10^{5}$ cpm/ug.)

iodinated lactoferrin for 30 minutes at $4^{\circ} \mathrm{C}$. Maximum lactoferrin levels (about $2.5 \mu \mathrm{g}$ ) were bound after adding $660 \mu \mathrm{g}$ iodinated ligand. Binding was not affected by the iron content of lactoferrin, as similar results were obtained using lactoferrin with loaded iron. Maximum transferrin binding to $T$ pallidum, on the other hand, always ranged from $0 \cdot 1 \%$ to $10 \%$ of that of lactoferrin under the same experimental conditions. For example, using $66 \mu \mathrm{g}$ and $660 \mu \mathrm{g}$ iodinated transferrin, the amounts of transferrin acquired by $T$ pallidum in duplicate samples were, respectively, $2 \%$ $(0.017 \mu \mathrm{g})$ and $4 \%(0.12 \mu \mathrm{g})$ of the lactoferrin bound by treponemes using the same amounts of iodinated lactoferrin.

\section{LACTOFERRIN RECEPTOR SPECIFICITY}

Competition for the lactoferrin receptor was observed when unlabelled lactoferrin was added to treponemes incubated with ${ }^{125}$ I-lactoferrin (fig 3). Unlabelled transferrin did not compete with iodinated lactoferrin for binding, which showed the specificity of treponemal acquisition of lactoferrin.

\section{UPTAKE OF IRON FROM LACTOFERRIN BY $T$} PALLIDUM

Finally, we examined the ability of $T$ pallidum to accumulate iron after lactoferrin binding. Figure 4 shows not only a direct relation between lactoferrin binding and iron accumulation in treponemes, but also indicates a disproportionate increase in ${ }^{59} \mathrm{Fe}$ 


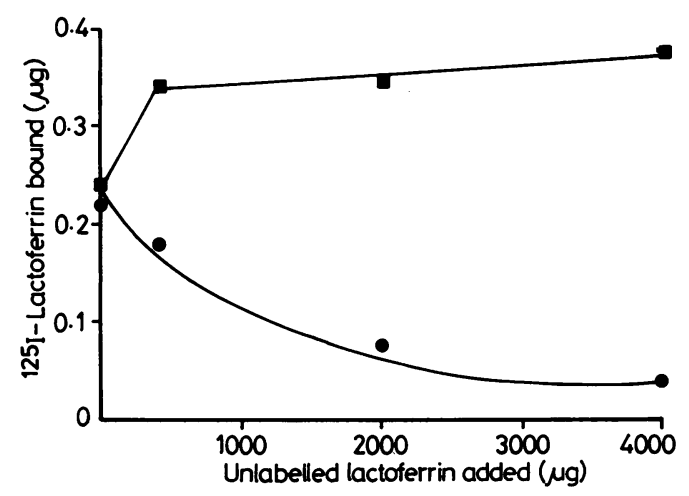

Fig 3 Specificity of lactoferrin acquisition by Treponema pallidum. (Treponemes $\left(0.5 \mathrm{ml}\right.$ volume of $\left.1.91 \times 10^{10}\right)$ were simultaneously mixed for 30 minutes at $4^{\circ} \mathrm{C}$ with $66 \mu \mathrm{g}$ iodinated lactoferrin and varying amounts of unlabelled lactoferrin (O) or transferrin (D).)

concentration compared with amounts of associated lactoferrin at the same times. On a molar basis, treponemes acquired six times more iron $(60 \rho \mathrm{mol})$ at $34^{\circ} \mathrm{C}$ than the steady state concentration of lactoferrin (about $10 \rho \mathrm{mol}$ ) at 30 minutes.

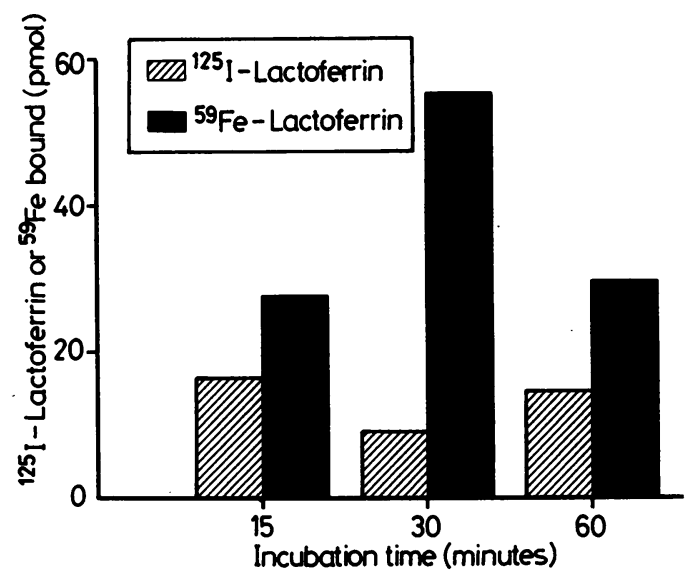

Fig 4 Time course of accumulation of radioiron $\left[{ }^{59} \mathrm{Fe}\right]$ by Treponema pallidum. (Treponemes $\left(1 \cdot 3 \times 10^{9}\right)$ were suspended in $0.5 \mathrm{ml}$ PBS with $1 \%$ BSA and incubated at $34^{\circ} \mathrm{C}$ for times indicated with $133 \mu \mathrm{g}$ lactoferrin labelled with radioiodine $\left({ }^{125} \mathrm{I}\right)$ or radioiron $\left({ }^{59} \mathrm{Fe}\right)$. Amount of radioactivity was measured. Specific activity for ${ }^{39} \mathrm{Fe}$-lactoferrin was $5 \times 10^{2} \mathrm{cpm} / \mathrm{\mu g}$ and for ${ }^{125} \mathrm{I}$-lactoferrin was $4.0 \times 10^{5} \mathrm{cpm} / \mu \mathrm{g}$.
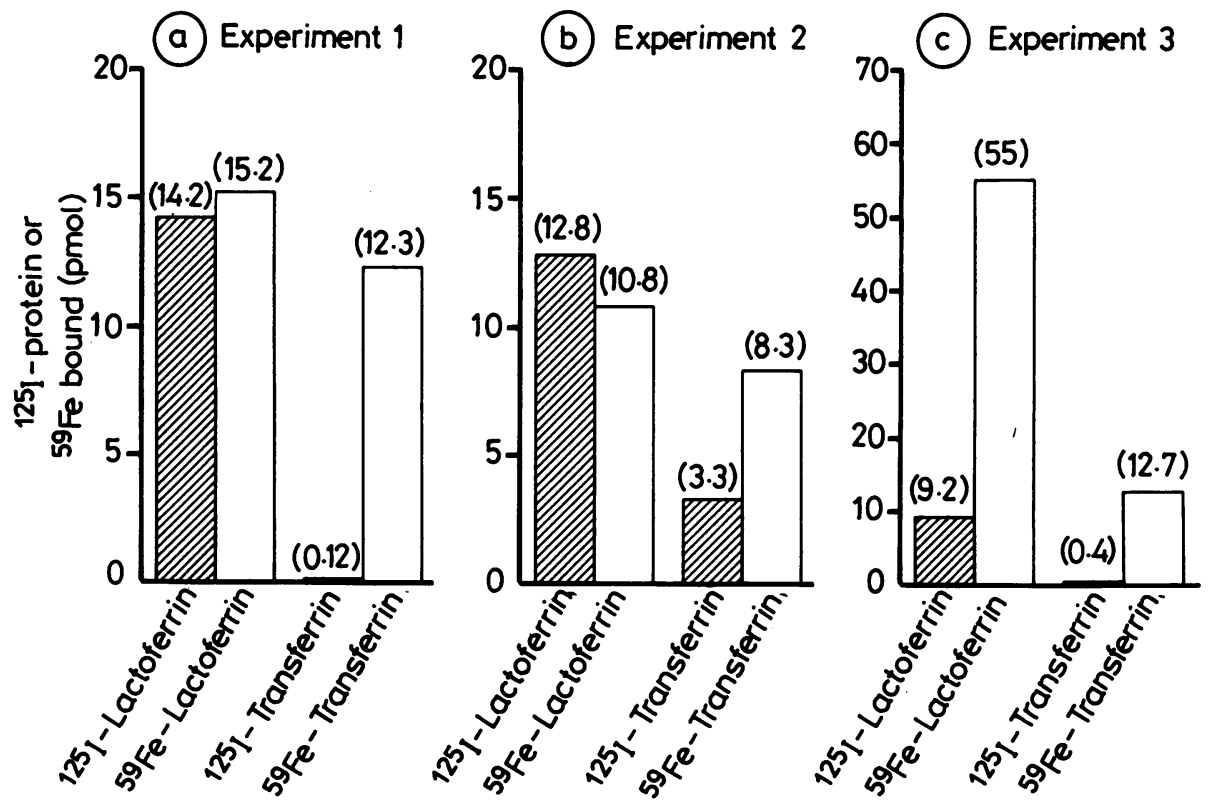

\section{Substrate used}

Fig 5 Iron accumulation by Treponema pallidum from lactoferrin and transferrin. (About $1 \times 10^{10}$ to $3 \times 10^{10}$ organisms in $0.5 \mathrm{ml}$ final volume of $P B S$ with $1 \%$ BSA were incubated for 30 minutes at $34^{\circ} \mathrm{C}$ with $133 \mu \mathrm{g}$ of ligands indicated. Specific activities were as follows: $7.0 \times 10^{5} \mathrm{cpm} / \mu \mathrm{g}$ for ${ }^{125} \mathrm{I}$-lactoferrin, $4.8 \times 10^{2} \mathrm{cpm} / \mu \mathrm{g}$ for ${ }^{59} \mathrm{Fe}$-lactoferrin, $5.0 \times 10^{5} \mathrm{cpm} / \mu \mathrm{g}$ for ${ }^{125} \mathrm{I}$-transferrin, and $7.5 \times 10^{3} \mathrm{cpm} / \mu \mathrm{g}$ for ${ }^{59} \mathrm{Fe}$-transferrin. Each experiment represents treponemes extracted from a different rabbit.) 
Similar experiments were performed using transferrin, and treponemes unexpectedly removed iron from ${ }^{59} \mathrm{Fe}$-transferrin to levels three to 100 times higher than those seen for the steady state binding of transferrin (fig 5). These data indicate that, although $T$ pallidum shows a smaller capacity to bind transferrin than lactoferrin, virulent treponemes remove and sequester from transferrin similar amounts of iron to those from lactoferrin.

\section{Discussion}

The inability to cultivate $T$ pallidum in vitro continues to be a major impediment to studying treponemal factors affecting the pathobiochemistry of syphilis. Recent reports reinforce the potential role of medium components, such as serum growth factors, ${ }^{13}$ in treponemal metabolic processes. We have been interested in defining the importance of the associations between pathogenic micro-organisms ${ }^{2}$ is and specific host molecules. ${ }^{24}$ is 16 Successful parasitism by $T$ pallidum already appears to depend on the acquisition of plasma fibronectin ${ }^{47}$ and possibly other undefined proteins. ${ }^{4}$ Host iron is usually bound to transferrin and lactoferrin, glycoproteins with high binding affinities for iron, which are found in serum and mucosal surfaces, respectively. Thus the binding of host proteins by $T$ pallidum may represent mechanisms by which these parasites acquire iron and thereby enhance their survival within the host environment.

It is clear that specific lactoferrin, but not transferrin, binding to $T$ pallidum occurs (figs 1-3), and this is followed by iron accumulation in treponemes after incubation with ${ }^{59} \mathrm{Fe}$-lactoferrin (figs 4 and 5). Furthermore, we observed an efficient uptake of iron from transferrin (fig 5) despite the lower steady state binding levels (figs 1 and 2). This observation may clarify the ability of the organisms to colonise mucosal surfaces as well as to cause disseminated infection.

During these studies it was not possible to assess whether treponemes possess specific iron chelators to remove iron bound to host protein from their surface. Alternative mechanisms for iron accumulation may also be active, such as the internalisation of lactoferrin followed by sequestration of iron and subsequent lactoferrin release.

It is important that treponemes obtained at peak orchitis from individual rabbits but extracted at different times showed varying maximum levels of lactoferrin binding (figs 1 and 5). Biological variability between treponemal populations in acquiring hostprotein has been reported previously,' and this variable has complicated the efforts made to compare this experimental system directly with other microbial models known to acquire iron binding proteins..$^{14} 18$

The acquisition of iron binding host proteins by $T$ pallidum by specific and non-specific mechanisms may relate directly to the parasitic capabilities of these pathogens. In addition to $T$ pallidum coating itself with host components to evade immune surveillance $e^{1-3}$ and treponemes using host fibronectin for adherence and in vivo targeting, ${ }^{4-7}$ other host proteins appear to be necessary for treponemal survival. ${ }^{4}$ Clearly susceptibility or resistance of the host to infection with $T$ pallidum may partly be related to the availability of nutrients such as lactoferrin and transferrin in the host at the sites of infection.

This work was supported by Public Health service grant AI-19566, Research Career Development Award KO4 AI00584 from the National Institute of Allergy and Infectious Diseases to JFA, and by training grant AI-07271 from the National Institute of Health. We thank Ms Diana Hinojosa for her secretarial help and Ms Juanita Morgan for her technical help.

\section{References}

1 Christiansen S. Protective layer covering pathogenic treponemata. Lancet 1963;i:423-5.

2 Alderete JF, Baseman JB. Surface-associated host proteins on virulent Treponema pallidum. Infect Immun 1979;26:1048-56.

3 Fitzgerald TJ, Miller JN, Repesh LA, Rice M, Urquhart A. Binding of glycosaminoglycans to the surface of Treponema pallidum and subsequent effects on complement interactions between antigen and antibody. Genitourin Med 1985;61:13-20.

4 Peterson KM, Baseman JB, Alderete JF. Treponema pallidum receptor binding proteins interact with fibronectin. $J$ Exp Med 1983;157:1958-70.

5 Thomas DD, Baseman JB, Alderete JF. Fibronectin mediates Treponema pallidum cytadherence through recognition of fibronectin cell-binding domain. J Exp Med 1985;161:514-25.

6 Thomas DD, Baseman JB, Alderete JF. Syphilis spirochete binds same fibronectin (Fn) peptide as host cell Fn receptor. J Exp Med 1985;162:1715-9.

7 Thomas DD, Baseman JB, Alderete JF. Enhanced levels of attachment of fibronectin-primed Treponema pallidum to extracellular matrix. Infect Immun 1986;52:736-41.

8 Baseman JB, Hayes EC. Molecular characterization of receptor binding proteins and immunogens of virulent Treponema pallidum. J Exp Med 1980;151:573-86.

9 Turner TB, Bauer JH, Diseker TH, Kluth FC. The viability of Treponema pallidum in refrigerated whole blood and in desiccated serum. Trans Assoc Am Physicians 1941;56:106-8.

10 Turner TB, Bauer JH, Kluth FC. The viability of the spirochetes of syphilis and yaws in desiccated blood serum. Am J Med Sci 1941;202:416-23.

11 Nelson RA. Factors affecting the survival of Treponema pallidum in vitro. American Journal of Hygiene 1948;48:120-32.

12 Nelson RA, Steinman HG. Factors affecting the survival of Treponema pallidum in vitro. Proc Soc Exp Biol Med 1948;68:588.

13 Wong GHW, Steiner B, Graves S. Effect of four serum components on survival of Treponema pallidum and its attachment to rabbit cells in vitro. Genitourin Med 1986;62:1-3.

14 Peterson KM, Alderete JF. Iron uptake and increased intracellular enzyme activity follow lactoferrin binding by Trichomonas vaginalis receptors. J Exp Med 1984;160:398-410.

15 Peterson KM, Alderete JF. Host plasma proteins on the surface of pathogenic Trichomonas vaginalis. Infect Immun 1982;37: 755-62.

16 Peterson KM, Alderete JF. Selective acquisition of plasma proteins by Trichomonas vaginalis and human lipoproteins as a growth requirement for this species. Mol Biochem Parasitol 1984;12:37-48.

17 Redhead K, Hill T, Chart H. Interaction of lactoferrin and transferrins with the outer membrane of Bordetella pertussis. J Gen Microbiol 1987;133:891-8.

18 McKenna WR, Mickelsen PA, Sparling PF, Dyer DW. Iron uptake from lactoferrin and transferrin by Neisseria gonorrhoeae. Infect Immun 1988;56:785-91. 